\title{
Uma nova espécie de Strebla Wiedemann, 1824 (Diptera, Streblidae, Streblinae) sobre Anoura caudifer (E. Geoffroy, 1818) (Chiroptera, Phyllostomidae, Glossophaginae) ${ }^{1}$
}

Gustavo Graciolli ${ }^{1}$

\begin{abstract}
Aвstract. A new species of Strebla Wiedemann, 1824 (Diptera, Streblidae, Streblinae) on Anoura caudifer (E. Geoffroy, 1818) (Chiroptera, Phyllostomidae, Glossophaginae). A new species of Strebla Wiedemann, S. carvalhoi sp. nov., collected, on Anoura caudifer (E. Geoffroy, 1818) from Southern of Brazil, is described. Drawings of the postvertex, occipital plates, gonopods and tergite VII are provided.
\end{abstract}

KeYwords. Anoura; bat; batfly; ectoparasite; Streblidae.

\section{INTRODUÇÃO}

O gênero Strebla Wiedemann, 1824 (Diptera, Streblidae, Streblinae) compreende 24 espécies restritas à Região Neotropical, que parasitam morcegos, principalmente, da família Phyllostomidae (GuerRero 1996). Apenas duas espécies são encontradas sobre morcegos filostomídeos da subfamília Glossophaginae, Strebla curvata Wenzel, 1976 e S. harderi Wenzel, 1976, as quais parasitam espécies de Glossophaga E. Geoffroy, 1818 e de Anoura Gray, 1838, respectivamente.

Neste trabalho, uma nova espécie de Strebla encontrada sobre o morcego glossofagíneo Anoura caudifer (E. Geoffroy, 1818), é descrita.

O material examinado está depositado na Coleção de Entomologia Pe. J. S. Moure, do Departamento de Zoologia, Universidade Federal do Paraná (DZUP) e no Museu de História Natural Capão da Imbuia (MHNCI), ambas instituições de Curitiba, Paraná.

\section{Strebla carvalhoi sp. nov.}

(Figs 1-3)

Cabeça. Frontoclípeo dividido em duas pequenas placas denteadas anteriormente. Olhos com sete a oito facetas. Láterovértice com três setas anteriores e três posteriores à sutura diagonal e quatro setas mais curtas e finas à frente dos olhos. Margem anterior do pós-vértice arredondada. Lóbulo occipital com duas a três setas espiniformes (Fig. 1).

Tórax. Área entre os arcos prescutais de setas, glabra. Sutura longitudinal não alcançando a sutura transversal. Prescuto com duas fileiras de setas transversais entre a sutura pigmentada e a sutura transversa. Mesepisterno com duas setas, uma anterior cerca de 1/4 do comprimento da posterior, após a fissura episternal. Metatíbias com duas macrossetas subapicais na face dorsal. Tíbias com um grupo de macrossetas apicais na face ventral. Basitarso III tão ou mais longo que os três tarsômeros subseqüentes somados.

Abdômen. Fêmea. Lóbulo do sintergito I+II com 15 setas. Tergito VII em forma de gota d'água com quatro setas (Fig. 2). Epiprocto com quatro macrosetas distais. Esternito VII dividido em dois escleritos sub-reniformes com nove a 12 setas em cada um. Macho. Lóbulo do sintergito I+II com 15 setas. Sintergosternito VII+VIII com uma seta ântero-lateral de cada lado. Tergito IX com três a quatro setas laterais e quatro a cinco mais curtas e finas ventrais, de cada lado. Esternito $\mathrm{V}$ com a margem anterior reta e a posterior côncava, com 11 setas mais longas que o esternito. Gonópodo (Fig. 3) quase retilíneo, levemente curvado no terço apical, seta acessória posterior à macrosseta.

Holótipo fêmea: BRASIL. São Paulo: Capão Bonito, Parque Estadual de Intervales, Carmo (600m), sobre Anoura caudifer, 10/V/2001, G. Bianconi, G. Graciolli \& I. Arnoni col. (DZUP). Parátipos: BRASIL. Paraná: Adrianópolis, Fazenda Primavera Tatuapeva (2451’07'’s; 4844’08'’W), 2 machos sobre Anoura caudifer, 05/VI/2001, J. Quadros

1. Contribuição ${ }^{\circ} 1423$ do Departamento de Zoologia, Universidade Federal do Paraná.

2. Departamento de Zoologia, Universidade Federal do Paraná. Caixa Postal 19020, 81.531-980 Curitiba-PR, Brasil. Endereço eletrônico: mingau@bio.ufpr.br 

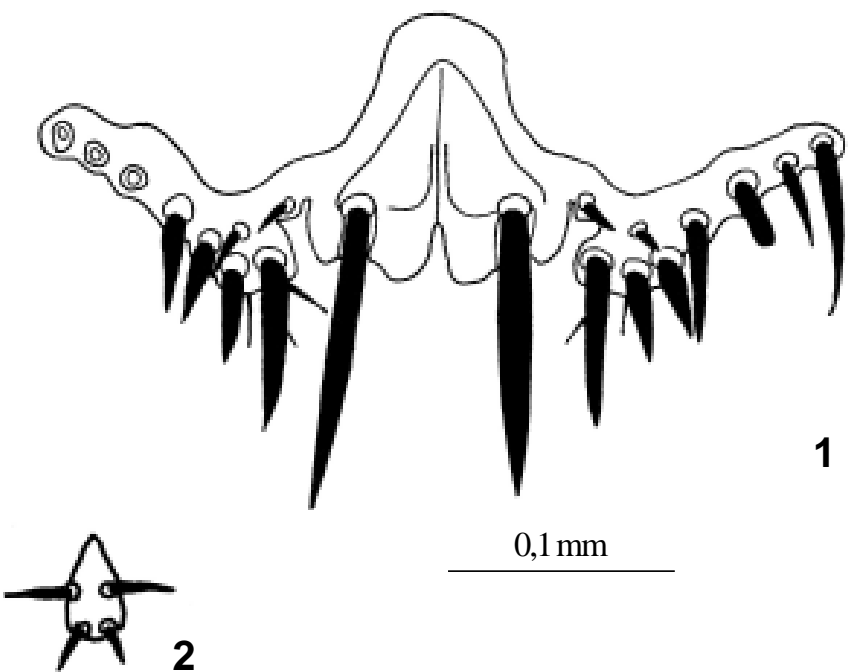

$0,1 \mathrm{~mm}$

2

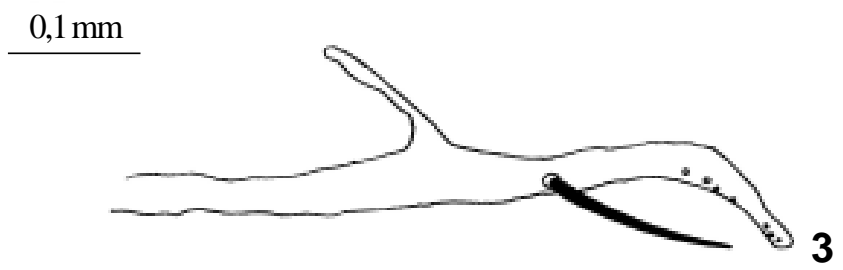

Figs. 1-3. Strebla carvalhoi sp. nov. 1, pós-vértice e lóbulos occipitais (parátipo macho), vista dorsal; 2, tergito VII (holótipo fêmea), vista dorsal; 3, gonópodo (parátipo macho), vista lateral.

\& A. Urben-Filho col. (MHNCI); Guaraqueçaba, Parque Nacional do Superagüí, Vila de Superagüí, 1 macho sobre A. caudifer, 13/XI/2001, G. Graciolli col. (DZUP); Pontal do Paraná, Estrada do Guaraguaçu, 1 fêmea sobre A. caudifer, 24/VIII/2001, L. Tiepolo col. (DZUP); Tunas do Paraná, Gruta de Campinhos, 1 fêmea sobre A. caudifer, VII/1947, Lang col. (MHNCI). Santa Catarina: Itapoá, Reserva Particular do Patrimônio Natural de Volta Velha, 1 macho (em lâmina) e 1 fêmea sobre A. caudifer, 26/XI/2000, G. Graciolli col. (DZUP).

Discussão taxonômica. Strebla carvalhoi sp. nov. é muito semelhante à Strebla guajiro (García \& Casal, 1965) e às outras espécies de Strebla que parasitam Glossophaginae, S. harderi e $S$. curvata. A nova espécie pode ser diferenciada pela forma e quetotaxia do pós-vértice, tergito VII, epiprocto, esternito VII, sintergosternito VII+VIII, tergito IX e gonópodos.

A forma da margem anterior do pós-vértice é arredondada, semelhante à S. harderi, enquanto em S. curvata e S. guajiro é truncada. Em S. carvalhoi sp. nov., o tergito VII tem a forma de gota d'água, seguindo o mesmo padrão encontrado em $S$. curvata e S. guajiro e diferindo de S. harderi, na qual o tergito é oblongo com as margens laterais retilíneas e mais longo que os das outras espécies. O esternito VII tem nove a 12 setas em S. carvalhoi sp. nov., sete em S. curvata, 17 a $18 \mathrm{em}$ S. harderi e 12 a 15 em $S$. guajiro. Em cada látero-vértice, há seis setas longas como em S. guajiro e S. harderi; em S. curvata encontramos sete. No sintergosternito VII+VIII, há uma seta longa e uma curta de cada lado, como em S. harderi e S. guajiro, e em S. curvata há apenas uma seta longa. No tergito IX, há sete a nove setas enquanto em $S$. curvata há oito a 12, em $S$. harderi oito a nove e em $S$. guajiro 10. O gonópodo é mais curto e menos curvado do que nas outras espécies.

Strebla carvalhoi sp. nov. é encontrada na região sul da Floresta Atlântica, nos Estados de São Paulo, Paraná e Santa Catarina, sobrepondo-se, em parte, com a distribuição de $S$. guajiro. Strebla curvata tem sido encontrada apenas na América Central (El Salvador e Panamá) e ao norte da América do Sul (Venezuela) (GuERRERo 1996); S. harderi apresenta uma distribuição disjunta, sendo encontrada na Venezuela e na região central do Brasil (Minas Gerais e Distrito Federal) (GuerRero 1996; Komeno \& Linhares 1999; Graciolli \& Coelho 2001); por sua vez, S. guajiro apresenta uma ampla distribuição geográfica, sendo encontrada do México ao sul do Brasil (Paraná) (Graciolli \& CaRVALHo 2001).

De acordo com o material examinado, Strebla carvalhoi sp. nov. é um parasito específico de Anoura caudifer. As outras espécies ocorrem em mais de um hospedeiro: $S$. curvata parasita Glossophaga commissarisi Gadner, 1962 , G. longirostris Miller, 1898 e G. soricina (Pallas, 1779); S. harderi já foi registrada sobre Anoura geoffroyi Gray, 1838 e A. latidens Handley, 1984 e S. guajiro parasita principalmente Carollia perspicillata (Linnaeus, 1758), podendo ser encontrada em outras espécies do gênero (WeNZEL 1976; GUERRERO 1996).

Etimologia. O nome desta espécie é em homenagem ao Prof. Dr. Claudio José Barros de Carvalho do Departamento de Zoologia, Universidade Federal do Paraná.

Agradecimentos. À Dra. Juliana Quadros e à M. Sc. Liliane Tiepolo pela coleta de parte do material examinado neste trabalho. Ao Dr. Fernando C. Passos por cessão do material proveniente de São Paulo. À M. Sc. Márcia Arzua, curadora do MHNCI, pelo empréstimo do material.

\section{REFERÊNCIAS}

Graciolli, G. \& C. J. B. DE Carvalho. 2001. Moscas ectoparasitas (Diptera, Hippoboscoidea) de morcegos (Mammalia, Chiroptera) do Estado do Paraná. II. Streblidae. Chave pictórica para gêneros e espécies. Revista Brasileira de Zoologia 18: 907-960.

Graciolli, G. \& D. C. Coelho. 2001. Streblidae (Diptera, Hippoboscoidea) sobre morcegos filostomídeos (Chiroptera, Phyllostomidae) em cavernas do Distrito Federal, Brasil. Revista Brasileira de Zoologia 18: $965-970$.

Guerrero, R. 1996. Catalogo de los Streblidae (Diptera: Pupipara) parasitos de murcielagos (Mammalia: Chiroptera) del Nuevo Mundo. VI. Streblinae. Acta Biologica Venezuelica 16:1-26.

Komeno, C. \& A. X. Linhares. 1999. Batflies parasitic on some phyllostomid bats in Southeastern Brazil: Parasitism rates and hostparasite relationships. Memórias do Instituto Oswaldo Cruz 94: 151-156.

Wenzel, R. L. 1976. The streblid batflies of Venezuela (Diptera: Streblidae) Brigham Young University Science Bulletin, Biological Series, 20: 1-177. 